\title{
NOTCHED LOW CYCLE FATIGUE OF ALLOY 718
}

\author{
A. Sridhar ${ }^{*}$, Vikas Kumar* ${ }^{* *}$ and A. K. Gogia* \\ * Project Office (Materials), Kanchanbagh, Hyderabad - 500058 (INDIA) \\ ** Defence Metallurgical Research Laboratory, Kanchanbagh, Hyderabad - 500058 (INDIA)
}

Keywords : Slot notch, Low cycle fatigue, Smooth specimen, Alloy 718

\begin{abstract}
Low Cycle Fatigue (LCF) damage is the life-limiting factor for rotating components in advanced gas turbines. LCF tests in laboratory are generally conducted in strain control using smooth cylindrical specimens. Smooth geometry may not represent actual component, as LCF life can be significantly influenced by notches present in components and the latter is not accounted by the data based on smooth specimens.

Most of the data available in literature is generated using circumferential or single or double edge notch. Use of circumferential notch may not be entirely appropriate for comparison with smooth fatigue specimens, because of difference in their diameters, as there is a decrease in volume or surface area of the specimen as the diameter decreases, and this is of significance, since fatigue failures usually start at the surface.

In the present study tangential slot notch was used to investigate the effect of slot notch on LCF behavior of Alloy 718 as it removes a very small percentage of the specimen cross-sectional area and does not cover entire circumference. So comparison can be made between the smooth and tangential notch specimens without much variation in their surface area or volume. The studies are conducted at ambient temperature and $650^{\circ} \mathrm{C}$ and a comparison is made with smooth specimen data. Results indicate that tangential slot notch also reduces significantly the fatigue life of alloy 718 .
\end{abstract}




\section{Introduction}

Low cycle fatigue (LCF) is the major form of damage incurred during service and is the lifelimiting factor for majority of rotating components $(\sim 75 \%)$ in advanced aero engines [1]. Life limiting factors are the presence of notches, keyways or change in the section thickness that cannot be avoided due to design considerations, as these geometrical discontinuities act as stress concentrators resulting in reduced fatigue life. Similarly, components in service may suffer foreign object damage (FOD) and presence of machining marks may also act as stress concentrators. Consequently, LCF tests conducted in laboratories using smooth cylindrical specimen may not be entirely appropriate, since LCF life of aero engine components can be significantly influenced by geometrical discontinuities. Cracks can initiate in gas turbine components at these geometrical discontinuities and can reduce fatigue life by several orders depending upon the stress concentration, testing conditions, temperature and microstructural parameters.

Alloy 718 is an important nickel-iron base superalloy designed for applications upto $650^{\circ} \mathrm{C}$, and is extensively used in fabrication of aeroengine compressor discs, where resistance to LCF at elevated temperature is an important requirement. Geometrical discontinuities present in compressor discs can act as stress concentrators and affect LCF life. Not much information is available in open literature on effect of notches on LCF life of alloy 718 under strain control loading condition. Effect of notches on LCF life of alloy 718 has been studied using double edge notch in stress control mode [2]. Studies have been performed to overcome the problem of time dependent notch sensitivity [3] and rotary bending fatigue in the presence of a partial notch [4].

Large amount of data available in literature on the effect of notches on fatigue life has been generated using circumferential notch. Use of circumferential notch may not be entirely appropriate, because of the difference in diameters between smooth and circumferential notch specimens. Due to a circumferential notch, there is a decrease in volume of the specimen [5]. In order to eliminate difference in volume between smooth and circumferential notch, a tangential slot notch was used to evaluate its effect on LCF life of alloy 718 in strain control, as it removes very small percentage of the specimen cross sectional area and covers only a small portion of the circumference [6]. So comparison can easily be made between the smooth and notch specimens without much variation in their volume/surface area. In the present study, effect of tangential slot notch on LCF life of Alloy 718 has been studied at $25^{\circ} \mathrm{C}$ and $650^{\circ} \mathrm{C}$.

\section{Experimental Procedures}

\section{$\underline{\text { Material }}$}

LCF specimen blanks were extracted from hot rolled bars of $20 \mathrm{~mm}$ diameter in as rolled condition. Nominal chemical composition of Alloy 718 is given in Table 1.

Table 1 : Chemical Composition of Alloy 718

\begin{tabular}{|c|c|c|c|c|c|c|c|c|}
\hline Element & $\mathrm{C}$ & $\mathrm{Cr}$ & $\mathrm{Fe}$ & $\mathrm{Mo}$ & $\mathrm{Nb}$ & $\mathrm{Ti}$ & $\mathrm{Al}$ & $\mathrm{Ni}$ \\
\hline $\mathrm{Wt}(\%)$ & 0.05 & 18.5 & Balance & 3.1 & 5.05 & 1.09 & 0.51 & 52 \\
\hline
\end{tabular}


Specimen blanks were subjected to conventional heat treatment (STA) consisting of a solution treatment (annealed for 1 hour at $950^{\circ} \mathrm{C}$, air cooled to room temperature) and a double aging treatment (aged for 8 hours at $720^{\circ} \mathrm{C}$, furnace cooled @ $55^{\circ} \mathrm{C} /$ hour to $620^{\circ} \mathrm{C}$ and held at $620^{\circ} \mathrm{C}$ for a 8 hours and subsequently air cooled to room temperature). Tensile tests were conducted on specimens in fully aged condition at $25^{\circ} \mathrm{C}$ and $650^{\circ} \mathrm{C}$ at a strain rate of $2 \times 10^{-3} \mathrm{sec}^{-1}$.

\section{$\underline{\text { LCF Tests }}$}

Tangential slot notch was machined using an electric discharge machine (EDM). Slot notch was machined on smooth specimen in the center of guage length of $12 \mathrm{~mm}$ having a guage diameter of $6.35 \mathrm{~mm}$ (dimensions of slot notch are $0.2 \mathrm{~mm}$ depth with a width of $0.4 \mathrm{~mm}$ ). Slot notch was cut on the specimen after removing all the circumferential marks, when the surface finish on specimen was $<0.2 \mu \mathrm{m}$ as per ASTM-E-606 [7]. Procedure for calculating stress concentration factor for slot notch is given by Manson and Hirschberg [8]. They assumed that the notch was machined entirely around the specimen in one method and in the second their assumption was that the specimen was square and that the notches were machined across two opposite faces. Both these methods indicated the stress concentration to be 3. Peterson [9] computed the stress concentration factors for both the configurations. We also assume same stress concentration factor of 3 for slot notch used in this study. Specimen used for fatigue testing is given below in figure 1 .
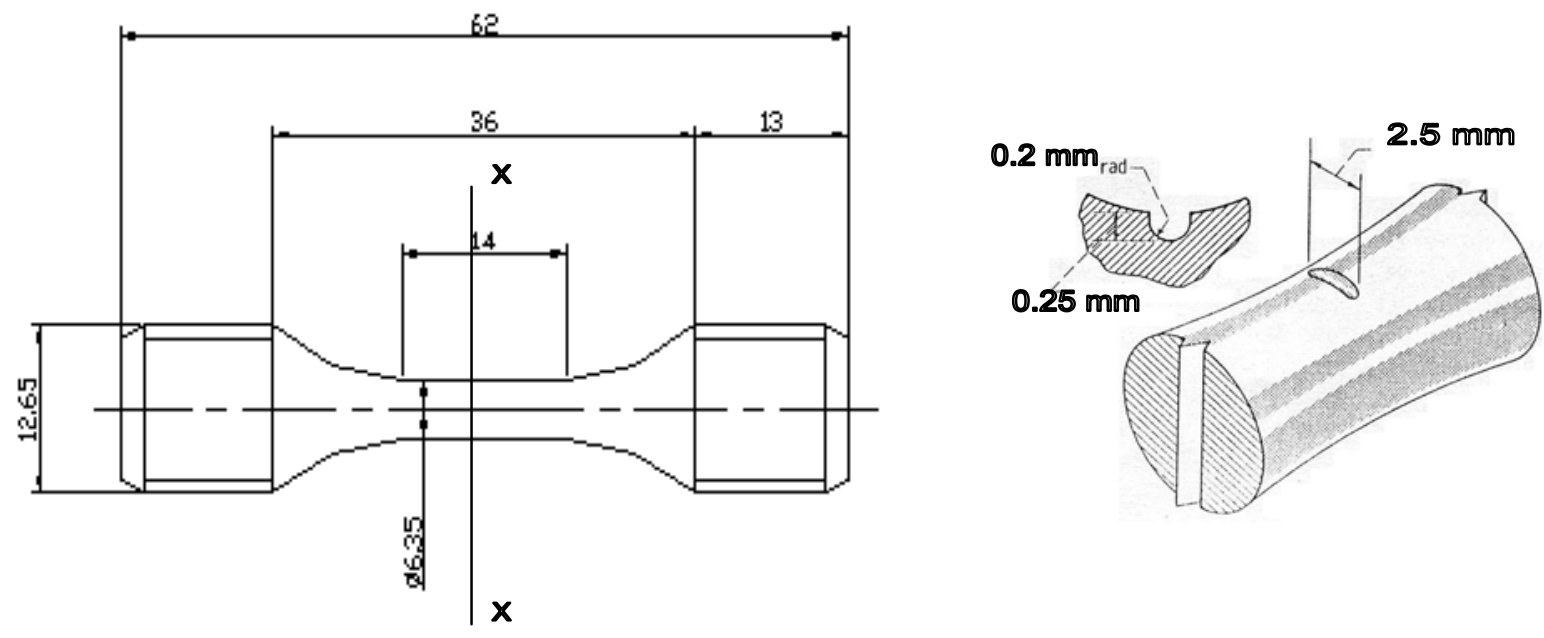

Section at X-X (from Ref. 12)

Figure 1. : Fatigue Specimen

LCF tests were conducted on Dartec test system (M1000RK) in tension-tension loading with $\mathrm{R}=0\left(0-\varepsilon_{\max }\right)$ in axial strain control with a frequency of $0.3 \mathrm{~Hz}$ using a triangular waveform for total strain ranges of $0.3-1.8 \%$. High temperature tests were performed in air environment.

Average grain size was estimated using a Leica image analyzer [10]. Fractography studies were done on a JEOL Scanning Electron Microscope (JSM 5410) after the samples were cleaned with 
acetone using an ultrasonic cleaner. Secondary electron mode was used for observing fractured surfaces.

\section{Results and Discussion}

\section{$\underline{\text { Microstructure }}$}

Microstructure in fully heat-treated condition revealed an average grain size of $7 \mu \mathrm{m}$ with spherical delta phase along grain boundaries as shown in figure 2 .

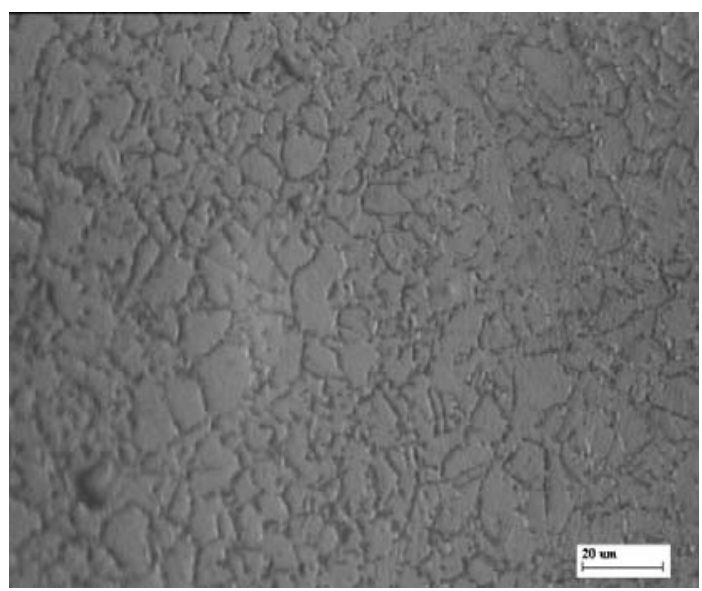

Figure 2 : Micrograph at 400X

\section{$\underline{\text { Tensile Properties }}$}

Results of tensile tests at $25^{\circ} \mathrm{C}$ and $650^{\circ} \mathrm{C}$ are presented in Table 2.

Table 2 : Tensile Test Results of Alloy 718 in STA Condition

\begin{tabular}{|c|c|c|c|c|}
\hline $\begin{array}{c}\text { Temperature } \\
\left({ }^{\circ} \mathbf{C}\right)\end{array}$ & $\begin{array}{c}\text { YS } \\
(\mathbf{M P a})\end{array}$ & $\begin{array}{c}\text { UTS } \\
(\mathbf{M P a})\end{array}$ & \%El. & \%R.A. \\
\hline 25 & 1255 & 1496 & 18 & 33 \\
\hline 650 & 1032 & 1166 & 21 & 52 \\
\hline
\end{tabular}

From the above results, it is observed that there is a decrease in yield strength and ultimate tensile strength with temperature. As expected, \%El. and \%R.A. increased with increasing temperature. Strength and ductility results of the current study are in agreement with property levels observed in alloy 718 used in aerospace industry [11].

\section{Notched Low Cycle Fatigue Properties}

Comparison of results of LCF tests with slot notch at $25^{\circ} \mathrm{C}$ and $650^{\circ} \mathrm{C}$ is shown in figure 3 . Total strain range vs. cycles to failure has been plotted on a log-log scale. 


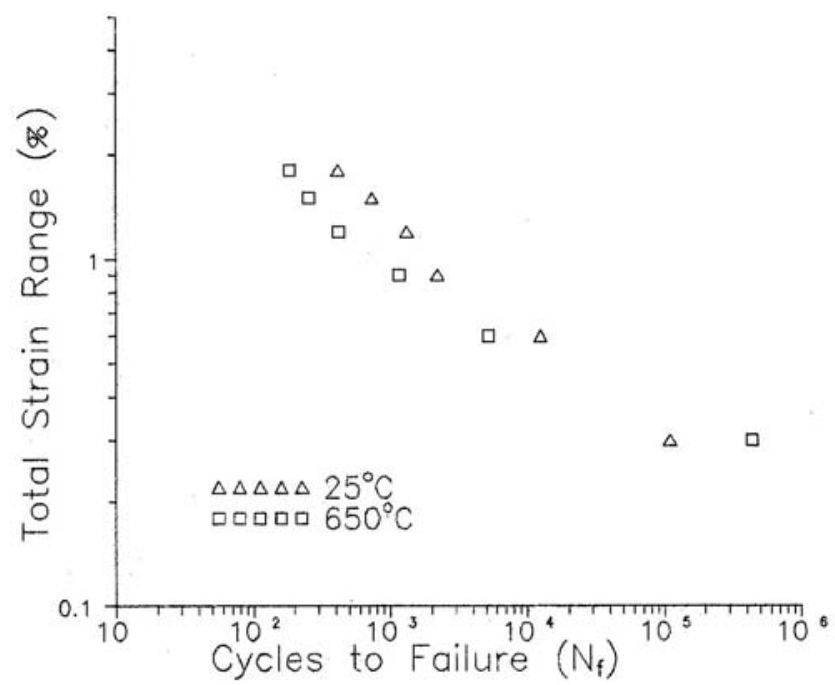

Figure 3 : Notched LCF Life at $25^{\circ} \mathrm{C}$ and $650^{\circ} \mathrm{C}$

In a normally expected trend, it is observed that fatigue life decreases with increasing total strain range at ambient as well as elevated temperature. It is also observed that the fatigue life of specimens at $650^{\circ} \mathrm{C}$ is lower than that corresponding to room temperatures in the range of $\sim 0.5$ $1.8 \%$ total strain range. Below $0.4 \%$ total strain range, the trend is reversed. Similar behavior in LCF life on smooth specimens in alloy 718 was observed by Sanders et al. [12]. These authors found that at higher strain ranges, the lower fatigue life occurred at higher temperatures, as generally expected. At lower strain ranges, they found that longer cyclic lives occurred at higher temperature. Reason attributed by Sanders et al. [12] for the inversion of LCF behavior in lower strain range regime is change in deformation modes from twinning to slip with increasing temperature. These authors found that deformation mode was twinning in temperature range of $200^{\circ} \mathrm{C}-430^{\circ} \mathrm{C}$ and predominant mode of deformation was found to be slip in the range of $540^{\circ} \mathrm{C}-$ $650^{\circ} \mathrm{C}$. In the present study characterization by transmission electron microscope is under way to understand the deformation mechanisms operating at higher and lower strain range as a function of temperature. Kawagoishi et al. [4] have also observed a similar behavior in their studies on rotating bending tests (stress controlled) containing partial notch in alloy 718 . These authors attributed the main reason for the suppression of small crack growth is crack closure caused by the oxidation of crack faces, leading to higher life at elevated temperature at low stress levels. They found that commencement of crack arrest and the length of arrested cracks at low stress levels is very similar to those at the fatigue limit, and this is the reason why the fatigue strength is higher at elevated temperature than at room temperature.

In the present study it is assumed that the longer life at low strain range and elevated temperature of $650^{\circ} \mathrm{C}$ could be attributed to oxidation of the crack surfaces resulting in crack closure and higher fatigue life, as the applied strain of $0.3 \%$ is low. Fractographic features at the crack initiation sites were observed on specimens tested at $0.3 \%$ total strain range at $25^{\circ} \mathrm{C}$ and $650^{\circ} \mathrm{C}$. Fractograph of room temperature specimen at $0.3 \%$ total strain range does not reveal any oxidation at the crack initiation site, whereas oxidation has been found to be present at the crack initiation site of specimens at $650^{\circ} \mathrm{C}$ as shown in figure 4 . 


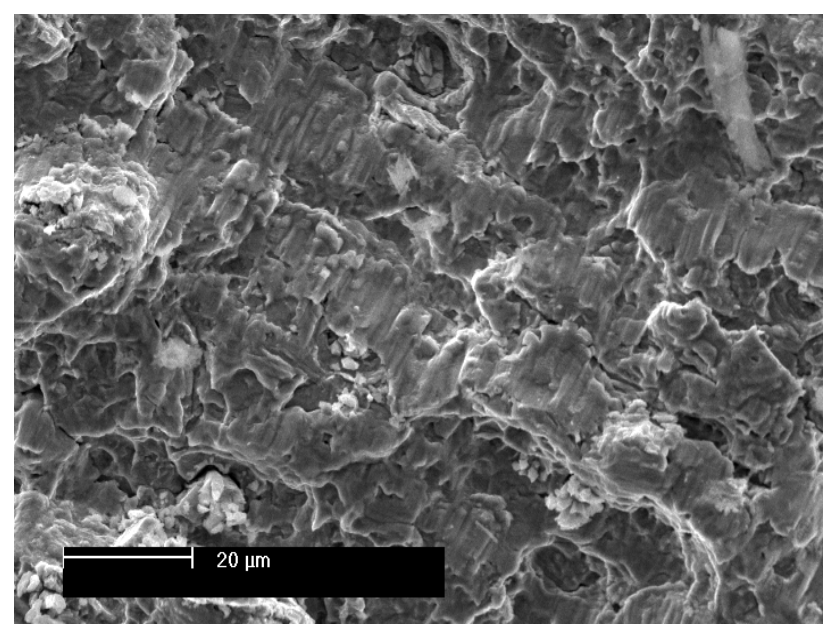

Figure 4 : Fractographic Features of Specimen at $0.3 \%$ Total Strain Range at $650^{\circ} \mathrm{C}$

Based on observation it is assumed that the lack of oxidation in $25^{\circ} \mathrm{C}$ specimen will not allow crack closure, whereas, the presence of oxidation at $650^{\circ} \mathrm{C}$ at crack initiation site leads to crack closure at low strain range. Crack arrest due to crack closure at elevated temperature at a total strain range of $0.3 \%$ may be the reason for higher LCF life at $650^{\circ} \mathrm{C}$ in the present study.

\section{Plastic Strain Amplitude versus Life}

Coffin-Manson (C-M) [13,14] relationship between plastic strain amplitude and fatigue life is given in figure 5 .

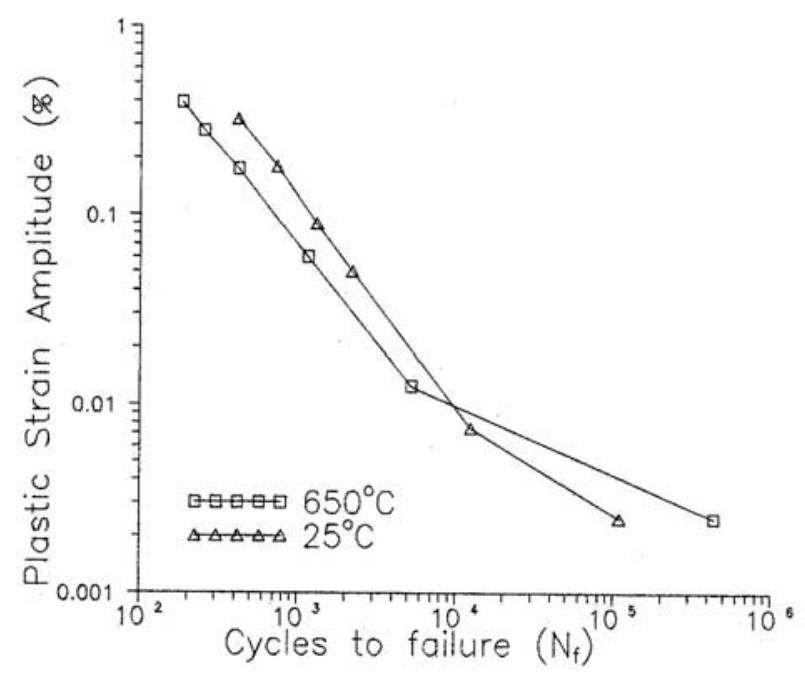

Figure 5 : Plastic Strain Amplitude Vs. Cycles to Failure of Slot Notch Specimens

C-M plot of slot notch fatigue specimens is found to exhibit a bilinear relationship between the plastic strain amplitude and fatigue life at $25^{\circ} \mathrm{C}$ and $650^{\circ} \mathrm{C}$. In the plastic strain amplitude range of $\sim 0.4-0.01 \%$, it is observed that LCF life at $650^{\circ} \mathrm{C}$ is lower than life corresponding to $25^{\circ} \mathrm{C}$. 
Below plastic strain amplitude of $0.008 \%$ (hyper), the trend is reversed. Slot notch fatigue data at room and elevated temperature can be represented by two distinct regions (hypo and hyper regions) with different slopes in each region. $\varepsilon^{\prime}{ }_{f}$ and $\mathrm{C}$ values for high and low strain amplitudes for two regions of the curves at $25^{\circ} \mathrm{C}$ and $650^{\circ} \mathrm{C}$ are given in Table 3 .

Table 3 : Coffin-Manson Parameters for Slot Notch in Alloy 718

\begin{tabular}{|c|c|c|c|}
\hline \multirow{2}{*}{$\begin{array}{c}\text { Temperature } \\
\left({ }^{\circ} \mathbf{C}\right)\end{array}$} & \multirow{2}{*}{$\begin{array}{c}\text { Portion } \\
\text { of Curve }\end{array}$} & \multicolumn{2}{|c|}{ Parameter } \\
\cline { 3 - 4 } & $\varepsilon_{f}^{\prime}(\mathbf{\%})$ & $\mathbf{C}$ \\
\hline 25 & High $\Delta \varepsilon_{p}$ & 206.50 & -1.108 \\
\cline { 2 - 4 } & Low $\Delta \varepsilon_{p}$ & 0.89 & -0.507 \\
\hline \multirow{2}{*}{650} & High $\Delta \varepsilon_{p}$ & 84.83 & -1.03 \\
\cline { 2 - 4 } & Low $\Delta \varepsilon_{p}$ & 0.28 & -0.364 \\
\hline
\end{tabular}

From table 3 it is observed that the ' $\mathrm{C}$ ' values of upper portion (High $\Delta \varepsilon_{p}$ ) of the curves are almost similar for ambient and elevated temperature. At elevated temperature the value of ' $\mathrm{C}$ ' is lower than the value of ' $\mathrm{C}$ ' at ambient temperature for lower portion of C-M plot (Low $\left.\Delta \varepsilon_{p}\right)$.

\section{Smooth versus Notched Fatigue Life}

Notched fatigue life at room temperature and $650^{\circ} \mathrm{C}$ is compared with smooth fatigue specimen data from Sanders et al. [12] and is given in figures 6 (a) and 6 (b) respectively.

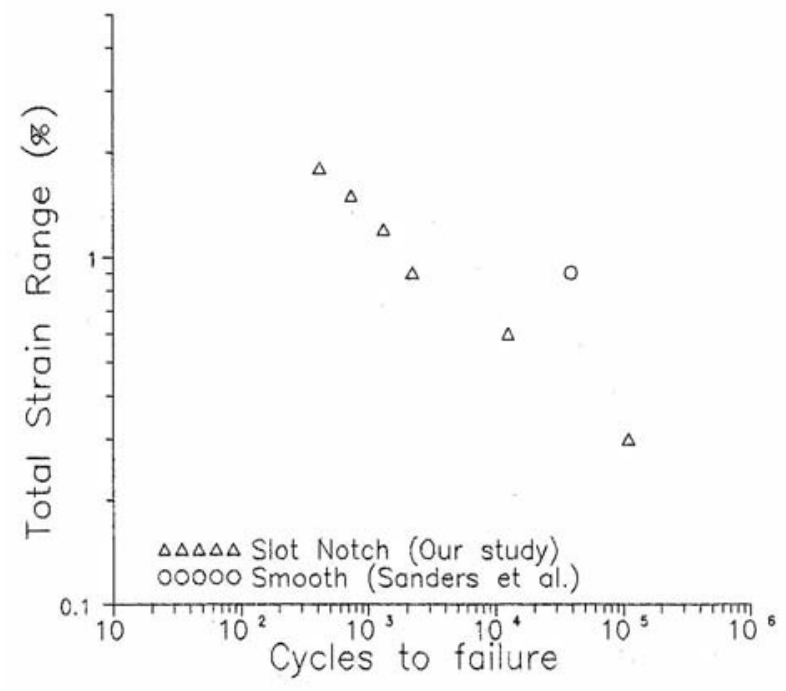

(a) At $25^{\circ} \mathrm{C}$

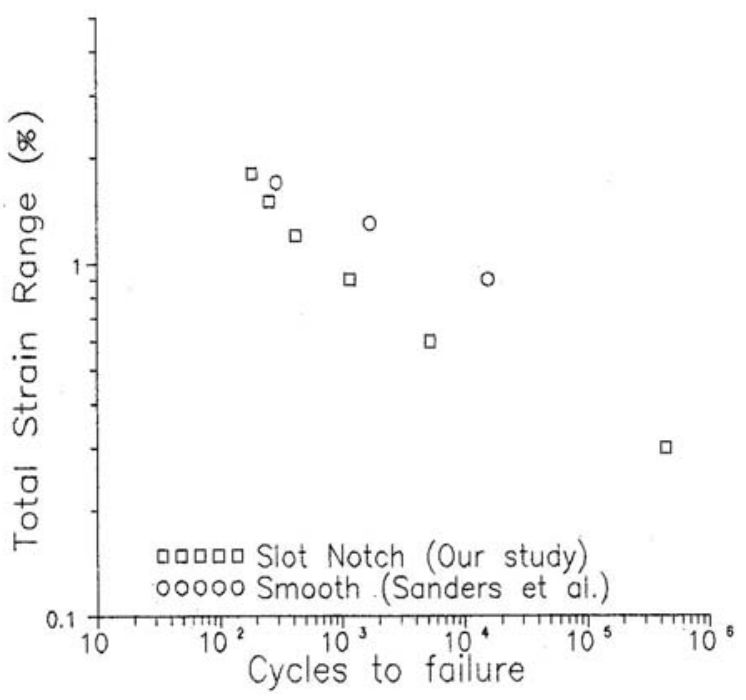

(b) At $650^{\circ} \mathrm{C}$

Figure 6 : Comparison of Smooth and Slot Notched Fatigue Lives 
From figure 6(a), it is observed that the fatigue life of slot notch is considerably lower ( one order) than smooth specimen. Smooth specimen data is from Sanders et al. [12] and only one room temperature data point is available. Parameters used for generation of smooth fatigue data by Sanders et al. are almost similar to the parameters used in current study. Similar comparison at $650^{\circ} \mathrm{C}$ as presented in figure $6(\mathrm{~b})$ indicates that the fatigue life of slot notch is again considerably lower than smooth specimen. At higher total strain ranges difference in fatigue lives between smooth and slot notch seems minimal and this difference in fatigue lives is found to increase with decreasing total strain range.

\section{Stress Response Curves}

Variation of stress range with life as a function of total strain range at $25^{\circ} \mathrm{C}$ and $650^{\circ} \mathrm{C}$ is shown in figure 7 (a) and 7(b) respectively.

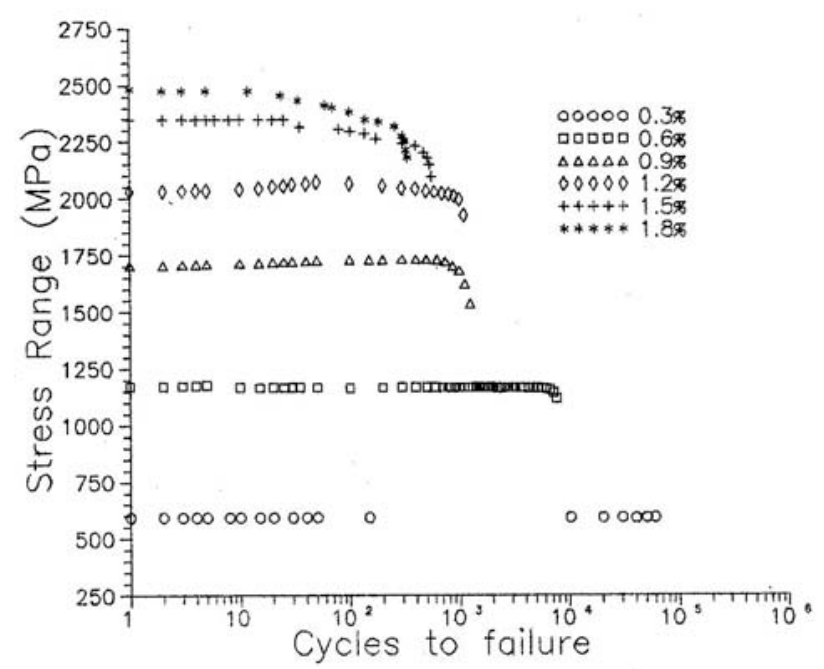

(a) At $25^{\circ} \mathrm{C}$

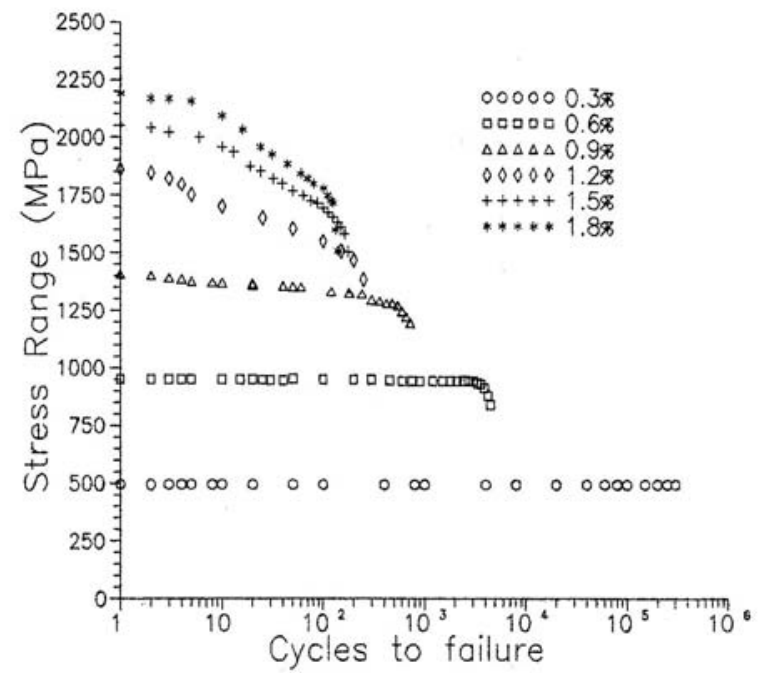

(b) At $650^{\circ} \mathrm{C}$

Figure 7 : Stress Range Versus Life of Alloy 718

At room temperature it is observed from figure 7(a) that the stress response is almost stable for majority of life for strain ranges $0.3 \%$ to $1.2 \%$. For strain ranges 1.5 and $1.8 \%$ small amount of softening is observed in the later part of life. No hardening was found at all the strain ranges at room temperature in the present study. It is observed that for all the strains ranges, stress got stabilized from the start of cycling followed by softening. Reasons for saturation of stress range can be attributed to the dynamic equilibrium between multiplication and annihilation of dislocations [15], which has been found in the total strain range of $0.3 \%$ to $1.2 \%$. From the above it can be concluded that the stress response of the material behavior is stable, even in the presence of a notch for majority of life. From figure 7(b) it is observed that the variation of stress range is almost constant till end of life for strain ranges $0.3 \%$ and $0.6 \%$. It is also observed that degree of softening increased with increasing total strain range from 0.9 to $1.8 \%$. Softening was found to be moderate for strain range $0.9 \%$ and increased substantially for strain ranges from 1.2 
to $1.8 \%$. It is also observed that for strains ranges 0.3 and $0.6 \%$, stress response got stabilized from the start of cycling almost till the end of life. At all other strain ranges, the material started softening from the start of cycling. Softening in INCO 718 has been attributed to several factors. Clark and McEvily [16] and Merrick [17] attributed softening to shearing of $\gamma^{\text {" }}$ precipitates by dislocations. Fournier and Pineau [18] had shown that in alloy 718 the deformation bands were only apparently denuded at precipitates and did not accept the hypothesis of Merrick [17] who attributed softening process to the dissolution of precipitates. Kalluri et al. [19] had noticed that at room temperature Inconel 718 under fatigue, channelization of deformation seems to occur in planar slip bands after $\gamma$ " are sheared during the initial stages of cycling. A detailed TEM study needs to be performed on fatigue specimens to determine the deformation mechanisms operative at ambient and elevated temperature to provide a definitive answer for softening behavior in 718 under the influence of a slot notch.

\section{Conclusions}

1. Notched fatigue life of alloy 718 is also reduced by the presence of a slot notch, even though it removes only a small amount of material from the specimen and is almost comparable to the surface area or volume of the smooth specimen. Fatigue life of slot notch specimen is lower than that of smooth specimens both at ambient and elevated temperature.

2. Plastic strain amplitude vs. fatigue life curves exhibit bilinear Coffin-Manson relation ship at ambient and elevated temperatures.

3. Fatigue life of slot notch specimens at elevated temperature \& low strain range $(0.3 \%)$ exhibit life higher than specimen tested under same conditions at ambient temperature.

4. Alloy 718 exhibits stable stress range over a major part of life at all strain ranges (0.3 to $1.8 \%$ ) at ambient temperature. At $650^{\circ} \mathrm{C}$ cyclic softening is observed at higher strain ranges $(1.5$ to $1.8 \%)$ and stable behavior at lower strain ranges $(0.3$ to $1.2 \%)$.

\section{$\underline{\text { References }}$}

1. T. Nicholas and J.M. Larsen,: in 'Fatigue : Environment and Temperature effects", (Editors : J. J. Burke and V. Weiss), 353-375, 1983, New York, Plenum.

2. R.G. Andrews, A.K. Koul, P.Au, "Fatigue crack initiation in Alloy 718 at $\mathbf{6 5 0}^{\circ} \mathrm{C}$," Editor E.A. Loria, Superalloys 718,625, 706 and Various Derivatives, (Warrendale, PA : The Minerals, Metals and Materials Society, 1991), pp943-954.

3. Hyman Feldstein and Omar Mendoza, "Analysis and elimination of time dependant Notch Sensitivity in Alloy 718," Editor E.A. Loria, Superalloys 718 - Metallurgy and Applications (Warrendale, PA : The Minerals, Metals and Materials Society, 1989), pp. 655-671.

4. N. Kawagoishi, Q. Chen and H. Nisitani, "Fatigue strength of Inconel 718 at elevated temperature", Fatigue Fracture of Engineering Materials and Structures, 23, 2000, pp209-216. 
5. George E. Dieter, 'Mechanical Metallurgy,' McGraw-Hill Book Company, London, 1988, p406.

6 M.H. Hirshberg, "A low cycle fatigue testing facility," Manual on low cycle fatigue testing, ASTM STP 465, American Society for Testing and Materials, 1969, pp.67-86.

7. ASTM E606, Annual Book of ASTM Standards, 3.01, 1993, pp.632-645.

8. S.S. Manson and M.H. Hirschberg, NASA-TN-D3146, 1965, p7

9. $\quad$ Peterson, R.E., "Stress Concentration Design Factors,; Charts and relations useful in making strength calculations for machine parts and structural elements", John Wiley and Sons, Inc., 1953.

10 D. Gopikrishna, S.N. Jha, and L. N. Dash, "Influence of microstructure on fatigue properties of Alloy 718," Editor E.A. Loria, Superalloys 718,625, 706 and Various Derivatives, (Warrendale, PA : The Minerals, Metals and Materials Society, 1997), pp. 567-573.

11. ASM Metals reference Book, $2^{\text {nd }}$ Edition, American Society for Metals, 1983, p407.

12. T.H.Sanders Jr., R.E. Frishmuth, and G.T. Embley, "Temperature dependent deformation mechanism of Alloy 718 in low cycle fatigue," Metallurgical Transactions A, 12A, 1977, pp.10031010

13. L F Coffin, Jr. : Trans ASME, 1954, Vol. 76, pp923-949

14. S.S. Manson,: "Behavior of materials under conditions of thermal stress", NACA-TR-1170 (supersedes NACA-TN-2933), National Advisory Committee on Aeronautics, 1954.

15. Christ and Mughrabi, "Microstructure and fatigue", in Low cycle fatigue and elasto-plastic behavior of materials, eds. K T Rie, et al., Elsevier London, 1997, pp59-69

16. Clark and McEvily, "Interaction of dislocations and structures in cyclically strained aluminum alloys," Acta Metallurgica et Materialia, 12, 1964, pp.1359-1372.

17. H.F. Merrick, "The low cycle fatigue of three wrought nickel-base superalloys," Metallurgical Transactions A, 5A, 1974, pp891-897

18. Fournier and A. Pineau, "Low cycle fatigue behavior of Inconel 718 at $298 \mathrm{~K}$ and 823K," Metallurgical Transactions A, 8A, 1977, pp.1095-1105.

19. Sreeramesh Kalluri, K. Bhanu Shankar Rao, Gary R. Halford, and Micheal A. Mc Gaw, "Deformation and damage mechanisms in Inconel 718 Superalloy," Editor E.A. Loria, Superalloys 718,625, 706 and Various Derivatives, (Warrendale, PA : The Minerals, Metals and Materials Society, 1994), pp 593-606. 